\title{
Giant Obstructive Myxoma with Hemolytic Anemia and Multiple Nevi in a 10-Year-Old Girl
}

\author{
John Jairo Araujo, MBBS, MASt, MD, MSIAC ${ }^{*}$ (D), Edwin Antonio González, MD², Rafael José Meza, \\ $M D^{3}$, Eliana María Arcila, $M D^{4}$ and Veronica Herrera Roldan, $M D^{5}$
}

${ }^{1}$ Department of Clinic and Research in Pediatric and Adult Congenital Heart Disease, Somer Incare Cardiovascular Center, Colombia

${ }^{2}$ Department of Pediatrics, Somer Clinic, Colombia

${ }^{3}$ Department of Congenital Heart Surgery, Somer Incare Cardiovascular Center, Colombia

${ }^{4}$ Department of Pediatrics, Remington University Corporation, Colombia

${ }^{5}$ Department of Pathology, Cito Pat Laboratory in Somer Clinic, Colombia

*Corresponding author: John Jairo Araujo, Department of Clinic and Research in Pediatric and Adult Congenital Heart Disease, Somer Incare Cardiovascular Center, Rionegro, 054040, Colombia, Tel: +5745624020

\begin{abstract}
Myxomas are low-prevalence heart tumors in the pediatric population. They are located in the left atrium in $75-86 \%$ of cases, and $30-50 \%$ are accompanied by general symptoms such as fever, weight loss, myalgias, arthralgias and elevated inflammatory markers caused by IL-6 release. They are rapidly growing heart tumors, and their most important complications are valvular and ventricular inflow tract obstruction, which may cause sudden death. Three to ten percent of cases are associated with Carney complex (CNC), type 1, caused by a mutation of the PRKAR1A gene on chromosome 17 . We present the case of a 10-year-old girl with general symptoms, a murmur, syncope, hemolytic anemia and multiple nevi, in whom a giant obstructive myxoma was found in the left atrium. Carney complex, type 1, was confirmed. She underwent successful surgical resection with no complications.
\end{abstract}

\section{Keywords}

Myxoma, Carney complex, Hemolytic anemia, Obstructive myxoma

\section{Case Report}

We present a 10-year-old female, who six months prior to consulting began experiencinggeneral symptoms consisting of fatigue, weakness, poor exercise tolerance, weight loss, intermittent fever of $39{ }^{\circ} \mathrm{C}$, progressive dyspnea and syncope with mild exertion in the last 30 days. She was referred to our cardiovascular center due to suspected bacterial endocarditis. On physical exam, she weighed $21 \mathrm{~kg}$, had a height of $138 \mathrm{~cm}$, a body mass index (BMI) of $11 \mathrm{~kg} / \mathrm{m}^{2}$, and a heart rate of 95 beats per minute. She had an increased left parasternal impulse, with increased intensity of the first sound, a normal second heart sound, a holodiastolic murmur and a systolic murmur radiating to the anterior axillary line. Her peripheral pulses were normal. She had multiple nevi on her face and a blue nevus on the top of her left foot. She had no significant family medical history. An electrocardiogram showed sinus tachycardia, and the chest X-ray was normal. A transthoracic echocardiogram showed a cardiac tumor with irregular borders adhered to the left side of the interatrial septum, with a tumor area of $10.8 \times 13.8 \mathrm{~cm}^{2}$. There was diastolic prolapse into the inflow tract as far as the trabeculated portion of the left ventricle (LV), causing obstruction of the mitral valve (MV) and LV outflow tract (Figure 1). In addition, there was moderate eccentric mitral regurgitation (MR) and left atrial (LA) dilation. The MV leaflets and subvalvular apparatus were normal. No other affected valves, or tumors at other sites, were found. Pulmonary pressure and LV function were normal. The labs

Citation: Araujo JJ, González EA, Meza RJ, Arcila EM, Roldan VH (2021) Giant Obstructive Myxoma with Hemolytic Anemia and Multiple Nevi in a 10-Year-Old Girl. Int Arch Cardiovasc Dis 5:043. doi. org/10.23937/2643-3966/1710043

Accepted: August 21, 2021: Published: August 23, 2021

Copyright: (C) 2021 Araujo JJ, et al. This is an open-access article distributed under the terms of the Creative Commons Attribution License, which permits unrestricted use, distribution, and reproduction in any medium, provided the original author and source are credited. 


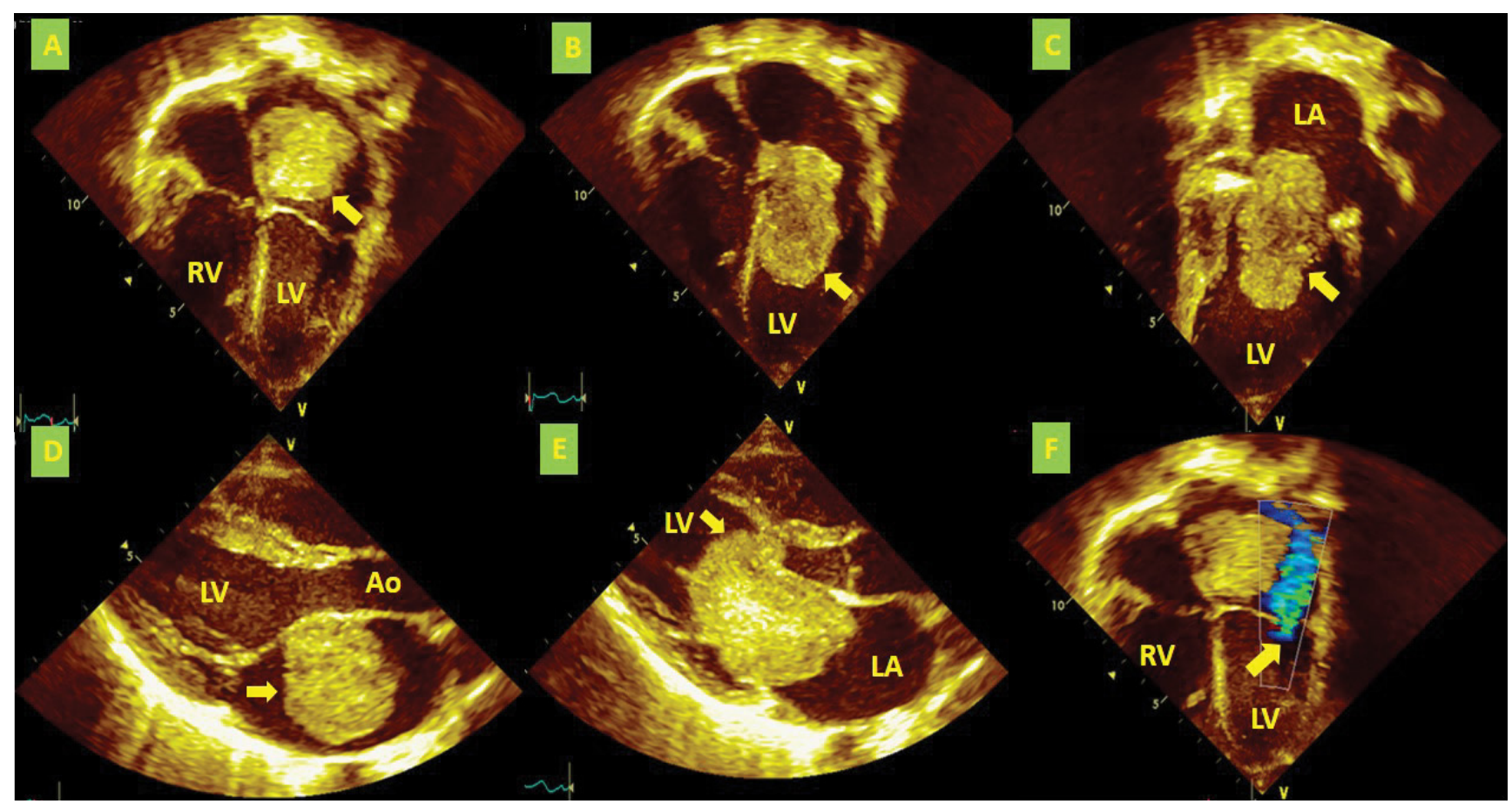

Figure 1: Echocardiography study (A) Apical four-chamber view showing a myxoma (yellow arrow) in the left atrium; (B) Diastolic prolapse of the myxoma (yellow arrow) into the inflow tract as far as the trabeculated portion of the LV; (C) Twochamber view showing the same image as Figure B (the yellow arrow indicates the myxoma), and a dilated LA; (D) Long axis view showing the myxoma (yellow arrow) in the LA; $(E)$ Long axis view showing the myxoma's (yellow arrow) diastolic prolapse into the inflow tract, causing obstruction of the mitral valve and LV outflow tract; (F) Apical four-chamber view showing eccentric mitral regurgitation (yellow arrow).

LA: Left Atrium; LV: Left Ventricle; RV: Right Ventricle; Ao: Aorta

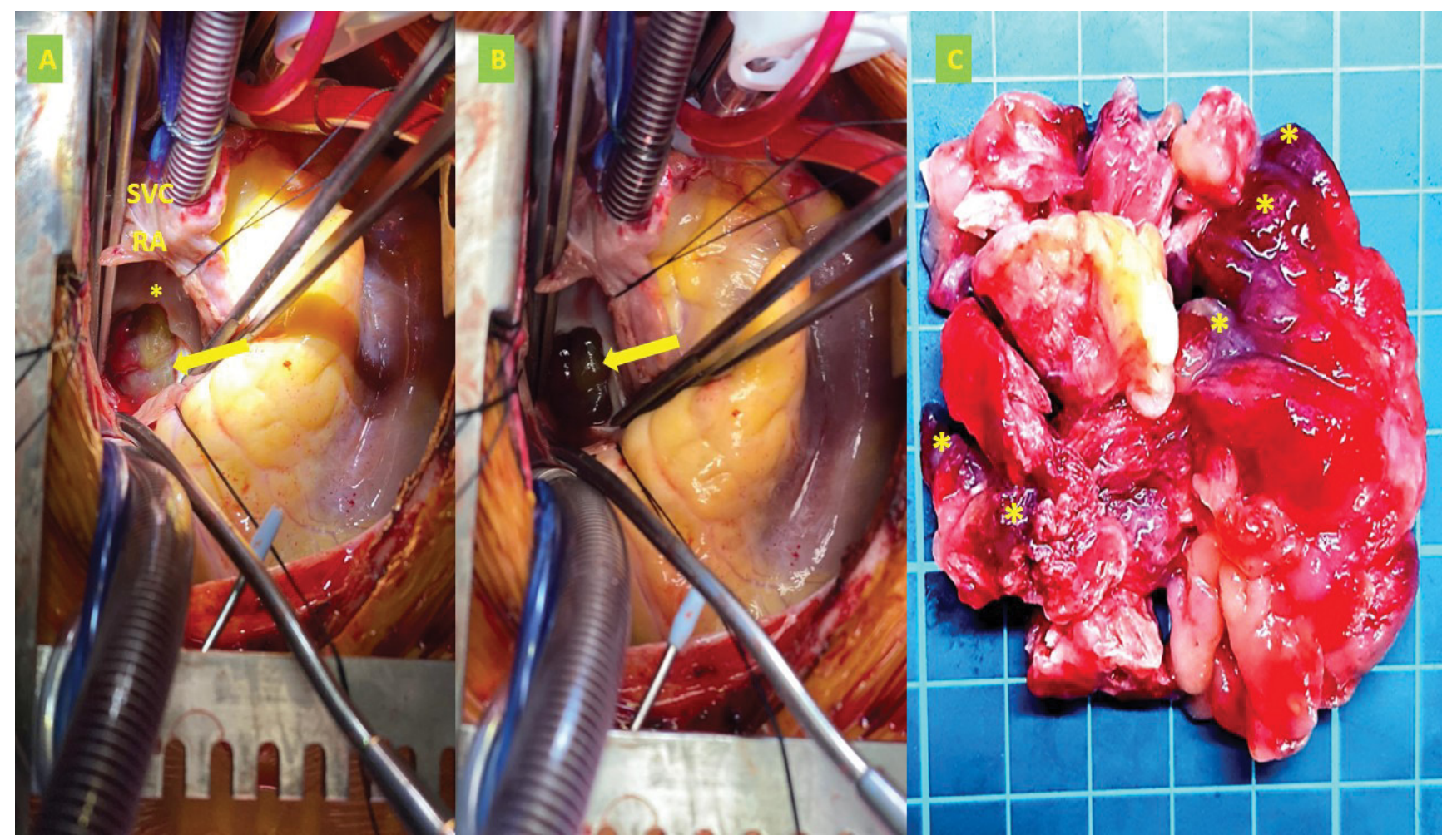

Figure 2: $(A)$ Cardiac surgery view through the open right atrium with partial resection of the interatrial septum; the yellow arrow shows the myxoma Partial resection of the interatrial septum (*); (B) Same view as in A; the yellow arrow shows hemorrhagic and congestive pedicle areas; (C) Macroscopic anatomic pathology showed a tumor with irregular borders, with a myxoid appearance, soft consistency, light color and hemorrhagic and congestive areas $\left(_{\star}\right)$.

RA: Right Atrium, SVC: Superior Vein cava with Cannula. 
showed a hemoglobin of $7.5 \mathrm{~g} / \mathrm{dl}$, normal leukocytes and platelets, and negative inflammatory markers and blood cultures. She underwent surgery with partial resection of the interatrial septum, complete transeptal tumor resection, and interatrial septum reconstruction with an autologous pericardial patch, with no complications. The anatomic pathology exam showed a tumor with irregular borders, weighing 23 grams and measuring $6 \times 6 \times 2 \mathrm{~cm}$, with a myxoid appearance, soft consistency, light color and hemorrhagic and congestive areas (Figure 2). Microscopic examination revealed a neoplasm formed by elongated cells with scant, poorly defined cytoplasm and oval and fusiform nuclei, within a myxoid, vascularized and hemorrhagic stroma (Figure 3). Calretinin, factor XIIIa, CD31, CD34 and vimentin immunohistochemical markers were positive (confirming a myxoma). The differential diagnosis included chronic inflammatory processes or metastatic carcinomas, which were ruled out by negative CD68 and cytokeratin (CK) immunohistochemical markers.

A genetic study confirmed CNC, type 1 , finding an $18.8 \mathrm{~kb}$ deletion on chromosome 17 (chr17:66.521,04266539,872 ) which involved exons $6-11$ on the PRKAR1A gene (NM_002734, 4). Echocardiographic follow up showed minimal MR and no residual tumor. She was discharged from our center after 21 days, without complications. She is currently in follow up and the family is being studied for CNC, type 1 .

\section{Discussion}

Primary heart tumors are a rare heart disease, constituting $0.001 \%$ to $0.028 \%$ of autopsy studies [1]. They may occur in all age groups, including newborns. They have a $0.17-0.2 \%$ prevalence in the pediatric population [2], with the following order: Rhabdomyomas $45-75 \%$, fibromas $6-25 \%$, and myxomas $5-10 \%$ [3]. In order of frequency, myxomas are found in the LA $(75-86 \%)$, right atrium $(20 \%)$, right ventricle $(5 \%)$, LV $(3 \%)$, and, less frequently, in the aortic valve and inferior vena cava [4]. They are rapidly growing tumors, gaining 1 to 2 grams/month. They can produce vascular endothelial growth factor, leading to angiogenesis and the presence of hemorrhagic zones. Large tumors are often complicated by obstructive phenomena when they are located in the ventricular outflow or inflow tracts. In some cases, they are found on autopsy as a cause of sudden death. Between 30 and $45 \%$ of myxomas in the LA are complicated by embolic events, with the central nervous system being the most affected (more than $50 \%$ of cases). Cases of retinal, renal, mesenteric, coronary or lower limb emboli have also been reported [5]. Other complications include arrhythmias, myocardial infarction, or tumor infection. The presented case had a large myxoma adhered to the left side of the interatrial septum over the fossa ovalis region, with high angiogenic activity evidenced by hemorrhagic zones, and accelerated growth which was causing obstruction of the LV inflow tract during

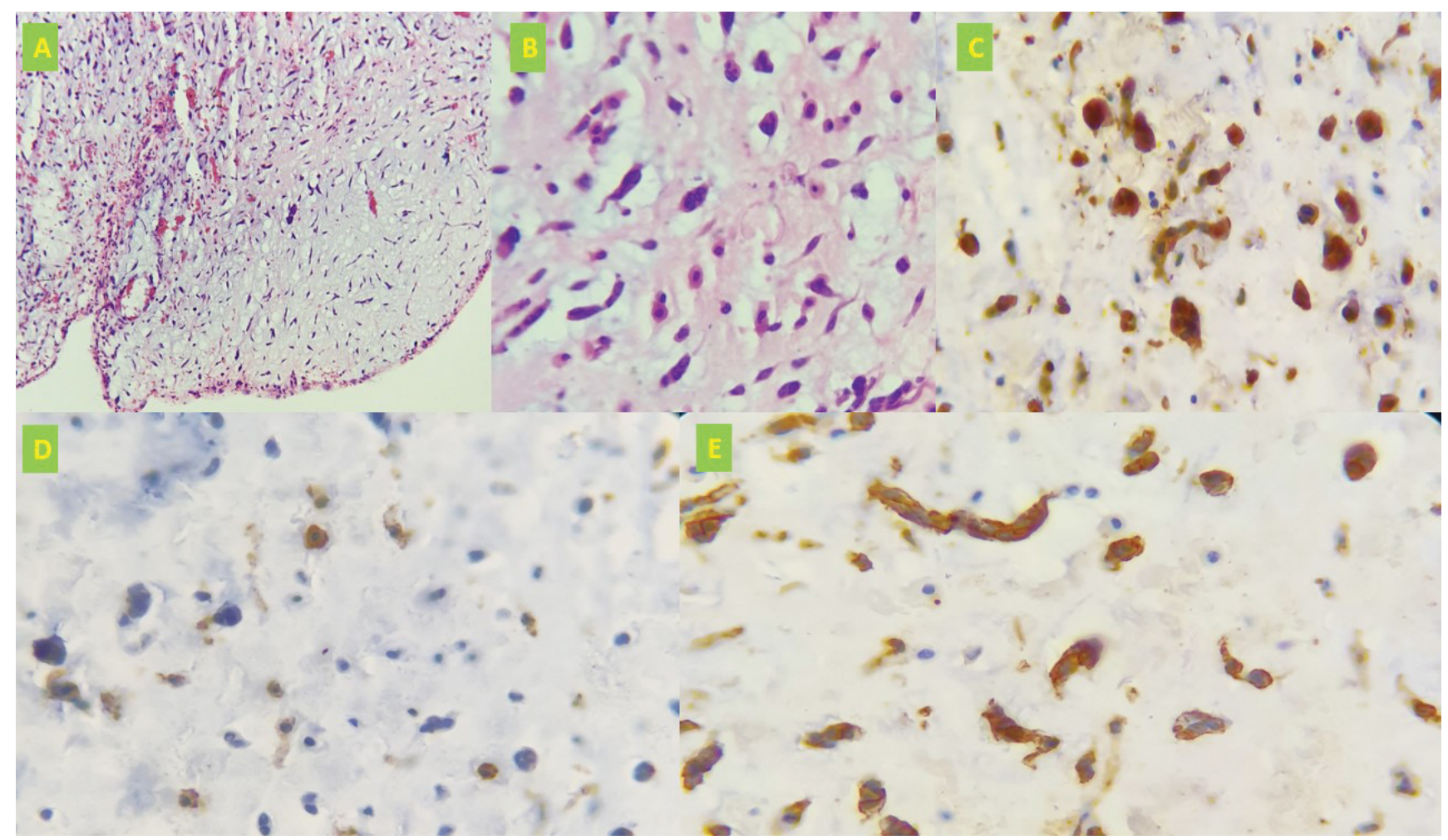

Figure 3: Microscopic anatomic study (A) Hematoxylin-eosin coloration, 10X magnification, showing vascularized myxoid stroma and elongated neoplastic cells with eosinophilic cytoplasm and ovoid nuclei; (B) 40X magnification showing sparse eosinophilic cytoplasm and nuclei with homogeneous chromatin; (C) Immunohistochemical markers (nuclear and cytoplasmic calretinin positive); (D) Immunohistochemical markers (CD31 positive); (E) Immunohistochemical markers (CD34 positive). 
diastole. In addition, a portion of the tumor was causing partial obstruction of the LV outflow tract (Figure 1). This led to low cardiac output with the slightest exertion and explains the syncope reported by the patient.

Myxoma growth can extend to the mitral annulus and affect valve function. In our case, we found no infiltration of the annulus or the leaflets. The MR found was secondary to annulus dilation (Figure 1). Thirty to fifty percent of cases have general symptoms such as fever, weight loss, myalgias, arthralgias, Raynaud's phenomenon, weakness and decreased functional class. In their study, Gabe, et al. showed that up to $74.2 \%$ of their cases presented with general symptoms [6]. This is important during the initial assessment and consideration of differential diagnoses like endocarditis or connective tissue disorders. These symptoms are attributed to the release of IL-6. Laboratory abnormalities such as a high erythrocyte sedimentation rate, anemia, leukocytosis, thrombocytopenia and elevated gamma globulins are also found [7]. In our case, the myxoma's large size and its constant prolapse into the LV inflow and outflow tracts were the mechanical conditions causing hemolytic anemia. This complication is described with some frequency in large tumors that prolapse into the ventricular inflow tracts [8].

Three to ten percent of myxomas originate in association with CNC, an autosomal-dominant condition that can result from PRKAR1A gene mutation [9]. The PRKAR1A gene codes for the CAMP-dependent protein kinase alpha regulatory subunit (R1-a). PRKAR1A gene mutations have been related to acrodysostosis 1 , with or without hormone resistance, and CNC, type 1 . This syndrome was first described by J. Aidan Carney in 1985
[10] as a new lentiginosis and myxoma syndrome, along with multiple neoplasia affecting (in addition to other organs and systems) several endocrine glands (adrenal, testicular, pituitary), with a characteristic tendency towards multicentric involvement (heart, breast, skin) and bilateral involvement in paired organs (adrenal glands and testicles). Diagnostic confirmation requires meeting two or more of the following clinical criteria, or one clinical criterion + one supplemental criterion (Table 1) [11,12].

In accordance with the literature, the multiple nevi found on the physical exam and the LA giant myxoma led to a strong clinical suspicion of CNC, which was confirmed with the detection of the PRKAR1A gene mutation on chromosome 17 , as well as the histopathological and immunohistochemical tests which confirmed the myxoma. It is important to diagnose CNC because tumors may develop in first-degree relatives, and the recurrence rate of the myxoma after resection may be $12-22 \%$, compared to sporadic forms which only have a $1-4 \%$ rate of recurrence [13]. Therefore, the recommendation of the experts is to follow up with serial imaging, as well as a genetic study of the firstdegree relatives [14]. This is currently being done with our patient.

Giant myxomas are a surgical emergency due to the complications described. Surgical resection is considered to be curative, with a low prevalence of complications [15].

\section{Conclusion}

This case teaches us that cardiac tumor may present with constitutional or systemic symptoms in the initial

Table 1: Diagnostic criteria for carney complex [modified from Correa R, et al. [12].

\begin{tabular}{|c|c|}
\hline \multicolumn{2}{|c|}{ Major diagnostic criteria for CNC } \\
\hline $\begin{array}{l}\text { Spotty skin pigmentation with typical distribution (lips, } \\
\text { conjunctiva and inner or outer canthi, vaginal and penile } \\
\text { mucosa) }\end{array}$ & $\begin{array}{l}\text { Large-cell calcifying Sertoli cell tumor (LCCSCT) } \\
\text { Myxoma* (cutaneous and mucosal) } \\
\text { Cardiac myxoma* }\end{array}$ \\
\hline $\begin{array}{l}\text { Breast myxomatosis }{ }^{*} \text { or fat-suppressed magnetic resonance } \\
\text { findings suggestive of this diagnosis }\end{array}$ & $\begin{array}{l}\text { Thyroid carcinoma* or multiple, hypoechoic nodules on thyroid } \\
\text { ultrasound in a child younger than } 18 \text { years }\end{array}$ \\
\hline $\begin{array}{l}\text { Primary pigmented nodular adrenocortical disease }{ }^{*} \text { or } \\
\text { paradoxical positive response of urinary glucocorticosteroid } \\
\text { excretion to dexamethasone administration during Liddle's test }\end{array}$ & $\begin{array}{l}\text { LCCSCT }^{*} \text { or characteristic calcification on testicular ultrasound } \\
\text { Psammomatous melanotic schwannomas (PMS)* }\end{array}$ \\
\hline $\begin{array}{l}\text { Acromegaly as a result of a growth hormone }(\mathrm{GH}) \text {-producing } \\
\text { adenoma* }\end{array}$ & Blue nevus, epithelioid blue nevus ${ }^{*}$ \\
\hline *Histological confirmation is required for these findings & $\begin{array}{l}\text { Breast ductal adenoma* } \\
\text { Osteochondromyxoma* }\end{array}$ \\
\hline
\end{tabular}


stages, followed by cardiovascular symptoms caused by their mechanical effects. The presence of multiple nevi should point towards the presence of a myxoma, as we proved in our case. Due to the association with CNC, type 1 , a genetic study was performed confirming a deletion on chromosome 17 involving the PRKAR1A gene. As a general recommendation, follow up is necessary due to recurrence and the possible appearance of these tumors in first-degree relatives.

\section{Acknowledgement}

To Somer Clinic director, Ethical Committee Somer Clinic and Genetix Laboratory for their support in this case.

\section{Conflicts of Interests}

We have no conflicts of interest to declare.

\section{Funding}

None.

\section{References}

1. Araujo J (2017) Right ventricular obstructive myxoma. Austin J Clin Cardiolog 4: 1057.

2. Marrsx G, Moran A (2008) Cardiactumors. In: Hugh A, Driscoll D, Shayddy R, Feltes T, Heart disease in infants, children and adolescents. ( $7^{\text {th }}$ edn), Lippincont, Williams and Wilkings, Batilmomre, USA, 1425.

3. Sabatine M, Colucci W, Shoen F (2006) Tumores cardíacos primarios. In: Ziper D, Lobby P, Bonew R, Braunwald E, Tratado de Cardiología. ( $7^{\text {th }}$ edn), Madrid, 1741-1755.

4. Auger D, Pressacco J, Marcotte F, Tremblay A, Dore A, et al. (2011) Cardiac masses: An integrative approach using echocardiography and other imaging modalities. Heart 97: 1101-1109.

5. Boutayeb A, Mahfoudi L, Moughil S (2017) Atrial myxoma: From diagnosis to management. Clin Surg 2: 1498.

6. Gabea E, Rodríguez C, Vigliano C, San Martino J, Wisner J, et al. (2002) Cardiac myxoma: Clinical-pathological correlation. Rev Esp Cardiol 55: 505-513.

7. Onubogu U, West B, Orupabo-Oyan B (2017) Atrial myxoma: A rare cause of hemiplegia in children. Cardiovasc J Afr 28: e1-e3.

8. Vuopio P, Nikkilä E (1966) Hemolytic anemia and thrombocytopenia in a case of left atrial myxoma associated with mitral stenosis. Am J Cardiol 17: 585-589.

9. Carney J, Gordon H, Carpenter P, Shenoy B, Go VL (1985) The complex of myxomas, spotty pigmentation and endocrine overactivity. Medicine (Baltimore) 64: 270-283.

10. Bosco M, Correa R, Graffigna P, de Miguel V, Fainstein Day P (2018) Carney complex review: Genetic features. Endocrinol Diabetes Nutr 65: 52-59.

11. Mateus C, Palangié A, Franck N, Groussin L, Bertagna X, et al. (2008) Heterogeneity of skin manifestations in patients with Carney complex. J Am Acad Dermatol 59: 801-810.

12. Correa R, Salpea P, Stratakis CA (2015) Carney complex: An update. Eur J Endocrinol 173: M85-M97.

13. Mahilmaran A, Seshadri M, Nayar P, Sudarsana G, Abraham K (2003) Familial cardiac myxoma: Carney's complex. Tex Heart Inst J 30: 80-82.

14. Karabinis A, Samanidis G, Khoury M, Stavridis G, Perreas $\mathrm{K}$ (2018) Clinical presentation and treatment of cardiac myxoma in 153 patients. Medicine (Baltimore) 97: e12397.

15. Vroomen $M$, Houthuizen $P$, Khamooshian $A$, Soliman Hamad M, van Straten A (2015) Long-term follow-up of 82 patients after surgical excision of atrial myxomas. Interact Cardiovasc Thorac Surg 21: 183-188. 